\title{
Integrated Ecology: The Process of Counseling with Nature
}

\author{
Michael J. Cohen \\ World Peace University
}




\title{
Integrated Ecology: The Process of Counseling with Nature
}

\author{
Michael J. Cohen
}

World Peace University

\begin{abstract}
Most personal, social and environmental stress results from our estrangement from nature's wise unconditional love within and about us. A new integrated ecology training program uniquely addresses this great challenge to the psychological community. Counseling students in natural areas over a thirty year period has produced ninety-seven unique nature-connecting activities that renew over forty-nine inherent sensory fulfillments. These ecopsychology activities reduce our estrangement, its pain and adverse effects. Natural inborn feelings of love and understanding express themselves. They catalyze responsible relationships that fill the emotional voids which fuel our destructive habits, dependencies and abandonment feelings. They give natural areas added value as rejuvenators of our biological and spiritual integrity.
\end{abstract}

Every moment of our lives, often without being aware of it, we relate to the world through multisensory perceptions shaped by our previous experiences. Dramatically, in August 1966, while deep in the bowels of the Grand Canyon National Park, a thunderstorm's fury vitalized my scientific perceptions. For me, the world changed forever. The storm fused my Newtonian and biological explanations of Earth's grandeur, landscapes and processes. When the sky cleared, in the sun's new light I deeply sensed Planet Earth as more than mechanical cause and effect relationships. Rather, it appeared to organize, regulate, preserve and regenerate itself, to act like a living being. That unique 
perception carved my destiny. In 1985, I conceived the National Audubon Society international symposium "Is the Earth a Living Organism?" It not only scientifically substantiated my Grand Canyon impressions, it laid the foundations for the study of Integrated Ecology. That science offers profound additives to counseling psychology (Cohen, 1988).

Guided by my living earth perceptions, in September, 1984, a yellow school bus and its occupants embarked on a nine month living and learning expedition. Outfitted with camping gear and a small library, it departed from Albany, New York carrying twenty students, my staff and me to a personal and academic growth utopia (Cohen, 1974). It began my 16th year sleeping out under storms and bright stars year round; camping exploring and teaching in America's natural areas.

This all-season, consensus-governed, outdoor-living program I founded in 1959, immersed its intimate school community in critical thinking, rich interpersonal experiences and natural wonders. Participants thrived in eighty-three different natural habitats, and from keeping their commitments to open, honest relationships with the natural environment, each other and with indigenous people(s), researchers, ecologists, the Amish, organic farmers, anthropologists, folk musicians, naturalists, shamans, administrators, historians and many others. The experience deeply connected our inner nature to the whole of nature.

As a result of our romance with educating ourselves this way, in the school community:

Chemical dependencies, including alcohol and tobacco, disappeared as did destructive interpersonal and social relationships.

Personality and eating disorders subsided.

Violence, crime and prejudice were unknown in the group.

Academics improved because they were applicable, hands-on, and fun.

Loneliness, hostility and depression subsided. Group interactions allowed for stress release and management; each day was fulfilling and relatively peaceful.

Students using meditation found they no longer needed to use it to feel good.

Participants knew each other better than they knew their families or best friends.

Participants risked expressing and acting from their deeper thoughts and feelings; a profound sense of social and environmental responsibility guided their decisions. 
When vacation periods arrived, nobody wanted to go home. Each person enjoyably worked to build this supportive, balanced living and learning utopia. They were home.

All this occurred simply because every community member met their commitment to make sense of their lives by establishing relationships that supported the natural world within and around them. We hunted, gathered and practiced such relationships; we organized and preserved group living processes that awakened our natural wisdoms. We learned to regenerate responsible relationships when they decayed. The secret to our success was to learn how to learn directly from the natural world, the living earth within and about us. Through natural sensations and feelings it taught us how to trust it, how to validate and incorporate its wisdom.

From thirty years of all-season travel and study in over two hundred sixty national parks, forests and sub-cultures, I developed a learning process and psychology that unleashes our natural ability to grow and survive responsibly. By documenting that it worked repeatedly and could be taught, I earned my doctoral degree and the school became a small, accredited graduate and undergraduate degree program.

To share my discovery with the public, in 1988 I encapsulated my nature-connected psychology in a series of ninety-seven sensory backyard and back country activities (Cohen, 1988, 1990, 1993). At the World Peace University, a non-governmental organization of the United Nations, I established and presently chair the Department of Integrated Ecology. The department trains counselors, educators, parents and students to incorporate these revolutionary activities in their work and lives. The simple, fun activities benefit people of all ages and backgrounds. Uniquely, they revitalize innate sensory communication and support between a person and the natural world.

Nature connecting activities balance our lives by letting natural connectiveness identify and be our common cause. By reducing stress while inducing participation, the activities promote recovery from destructive habits, dependencies and dysfunction. Today professionals use them to augment counseling, twelve-step, hospice, stress management, conflict resolution, self-esteem, and environmental education programs (Cohen, 1993). They enable us to follow Job's suggestion: "Speak to the Earth and it will teach thee." 


\section{Us: Identifying our Essence}

Because Integrated Ecology honors the responsible, ever-changing perfection of the global life community, it studies the fabric of that community's ability to relate and grow harmoniously through natural attractions. That fabric, which we each biologically inherit, unifies life relationships rather than further subdividing Earth into isolated academic and institutional cubbyholes. In reality and imagination integrated ecology returns us to our origins. There we critically measure information, procedures and behaviors by their natural attractiveness and long term effects. We then, moment by moment, responsibly organize and balance our relationships by amalgamating our natural attractions.

An essence of integrated ecology is the use of $U s$, a singular, powerful, culturally familiar symbol. In scientific, educational and spiritual ways, Us lastingly awakens and supports the dormant harmonic unity of global wholeness that lies within us. Critical thinking, research and history about Us enjoins most personal, intercultural and interspecies relationships. Eclectically, Us bridges the destructive gaps between religion and science by reinforcing what these two ways of thinking hold in common.

The spiritual view of Us respects, rather than negates, that most western people believe the following: During the sixth day of creation, (Genesis 1:26) before people are created, The Creator speaks with somebody or some things present. The Creator refers to us and our on that sixth day saying "Let us make man in our image, after our likeness." Who is this us and our? Since people have not yet been created, the Creator can't be speaking to humanity. All that exists at that moment is God and His or Her creation. For this reason, God may be speaking to "His spirit moving upon the face of the waters, to Earth and everything that creepeth upon the earth" (Genesis 1-25). This suggests that Us is the natural world that exists in ourselves and the environment. Us is God's nature, spirit and love.

New research affirms that natural people and natural areas are Us. For example, researchers now report that the word Indians comes from Columbus calling the nature-loving new world people he met en Dios, meaning with God. The sciences of Biology, Paleontology, Geology, Physics, Anthropology and Philosophy as well as most cultures and religions agree that the human species did not create, but rather arose from and after the natural world was already established. This aligns with spiritual outlooks. It suggests that we are a seamless continuum of Us, 
having "one Breath." (Ecclesiastes 3-19). Scientifically, God making man out of dust from the soil (Genesis 2:7) to create human being also confirms Us. The word human has its roots in humus, a fertile forest soil. Just one teaspoon of humus consists of water, minerals and many other species: five million bacteria, twenty million fungi, one million protozoa and two hundred thousand algae. This coincides with our bodies containing water, minerals and ten times as many cells of non-human species as human cells. Over half our body weight consists of the weight of "foreign" microorganism species; over one hundred fifteen different species alone live on our skin. In addition, natural attractions make the natural world physically flow through us. Every five to seven years every molecule in our body attracts and is replaced, atom by atom, by new molecules from the environment. Constantly, the natural world becomes us, we become it. Furthermore, scientists observe that a shared global balancing mechanism guides and integrates us and every other natural being.

From these interdisciplinary findings, Integrated Ecology views our lives and nature as Us. Us and we are each other. Us is our own and every other person's true inner nature bound to Us, the natural world, God's unadulterated nature. This helps explain why most of the world's great leaders "received the word" by spending long periods of time in wilderness, en dios.

Each of us is naturally born as Us, free of cultural stories and dogma. I and others gain harmonious wisdom as we rationally choose to connect with Us in ourselves, others and the environment. By culturing our connectedness with Us, we enjoy peace with the whole (Holy) of nature found in ourselves, others and the land. We feel upset when we hurt any part of Us, for we feel that hurt. Because we recognize the validity of Us, we validate our hurt feelings and their messages as well as our good feelings. Through this process our inner pain enjoins with our natural attractions. Together, they guide us to live responsibly for our pain not only subsides as our natural trespasses subside, it is replaced by joy.

\section{The Wisdom of Us}

I have been trained as a scientist. When hearing about, but not experiencing Us, some say I've been in the woods too long and it shows. However, I suggest we measure my experiences with Us by their long term effects. When I compare these effects to the personal and global effects of our excessively nature-separated society, I conclude that most of us have not yet been in the woods long enough. Decades of outdoor 
sensory learning and research show me that Us has no spoken or written language. Although functionally illiterate, Us is a beautiful, intelligent global life community that exists within and around us. Us survives by continually organizing, preserving and regenerating all of itself, including people(s) that heed and respect its callings. When undisturbed, Us globally approaches an ever-changing, self-regulating, balanced perfection, an optimum of life and diversity without garbage, war, or pollution; without excessive crime, insanity, stress, unhappiness and violence. When allowed to express itself, Us heals scarred landscapes as well as our personal bruises, emotional wounds and destructive relationships. With the exception of our cultural training to separate from, rather than embrace Us, we are to the natural world as our leg is to our body. For this reason, what happens to the natural world happens to us and vice versa. You see, it is no coincidence that our personal, social and environmental problems escalate in unison.

\section{The Underlying Problem}

Most problems result from the difference between how Us works and the way our cultural conditioning teaches us to think. Our thinking is based on language stories, it seldom incorporates the non-languaged, sensitive globally-supportive ways of Us. We survive by believing a misguided spoken and written cultural story. It says: 'To survive, conquer Us. Constantly grind Us into grist for building an overprotective indoor world.' However, since we are Us, as we separate from, conquer and hurt Us in the environment, we do the same to Us in ourselves. Us within us senses painful natural relationship ruptures and abandonment from the whole of Us. We suffer stressful feelings that limit our participation in relationships. That stress and apathy often produce dysfunction and continual cravings for support and pacification. Society teaches us to fulfill these cravings through further involvement and excellence in our misguided cultural stories and ways. This vicious circle is the core of our problems.

Degradation on many fronts conclusively demonstrates that our cultural story misleads us. To reverse it, integrated ecology teaches a more reasonable story. It says: 'We may best sustain ourselves by being reasonable, by sensing, articulating, validating and participating in Us, the whole of life.' To accomplish this we must learn to hear and speak Us's non-verbal language with which we are born. Us in us knows it. Indeed, every species and individual biologically inherits this blueprint. By using critical thinking, integrated ecology makes us aware in reason 
and language of what we already know inherently in our other natural sensitivities.

From early in our lives, our authorities seldom teach us to nurture Us. Out of respect, fear or dependency, we habitually internalize our authorities and their conquering ways in our thinking. Throughout our lives, within and about us, they thwart, rather than encourage, connections with Us. Studies show that out of habit, internal and external authority forces compel the average American to spend over ninety-five per cent of his or her life indoors. Laws require that we spend almost eighteen thousand developmental childhood hours in classrooms alone. Collectively, we spend less than one day per person per lifetime in tune with the natural world. We live over ninety-eight per cent of our adult lives abstractly knowing Us through detached stories about Us rather than through intimate contact with and enjoyment of the fullness of Us.

Studies show that people born and raised in a closet have and cause problems resulting from traumatic sensory deprivation. Hurt and unspirited, even when liberated from their confines closeted people fearfully cling to their closeted ways. How different are we from them? Born and raised bewildered (wilderness-severed) in a nature-isolated closet, our growth and development bonds us to indoor authorities, artifacts, stories and isolation, not to Us in ourselves, others and the natural world. Our sensory deprivation, fear and ignorance of Us stressfully engineers our nature. It aggravates and deteriorates our inborn awareness of Us. Even when outdoors, we habitually think and act in ways foreign to the natural world. Bewildered, we helplessly seek help from equally closeted, helpless helpers. How can we more effectively deal with our nature-estranged imprisonment and its adverse effects?

\section{The Substance of Integrated Ecology}

Let reason prevail. To be part of a system, any being must somehow be in communication with that system. Otherwise, that being has no clue what the system is doing and vice versa, so it can't be part of it. Indisputably, Us on Planet Earth is a global life system of which people are part. Therefore, it must communicate with us and vice versa. How? It communicates with us in the same way that it communicates with every other species and mineral, through natural attractions and affinities. We register them through our natural senses and feelings including our senses of reasoning and language. However, since our cultural survival programming says "conquer nature," we educate ourselves to remove 
most of nature's feelingful callings from our thinking. We disconnect from them by demeaningly labeling them 'the little child within us,' 'immaturity,' 'subjective,' 'unreasonable,' 'emotionality,' 'impulsiveness,' 'unscientific,' 'dirty,' 'satanic,' 'neurotic,' etc. These labels hide nature's biological rights and cries for compassion, mercy and equality within and about us. The labels not only encourage our habitual disconnected thinking, our closeted reasoning and language senses, to assault Us within and without, but by inquiring our many other natural sensitivities they immunize our thinking from the outrageous effects of its assault on Us.

The discipline of Integrated Ecology reverses our adverse disconnectedness from Us. It recognizes that we will not teach the natural world to speak English, so it makes sense for us to learn nature's unspoken language. In each of us that language consists of good natural feelings. Creating many kinds of enjoyable feelings for natural attractions is how Us in us makes sense at every level. Reasonably relating to Us unleashes these good feelings. They entice our sense of reason to demand that we continue our enjoyable, reasonable sensory relationships with Us. Motivated by the joys of being reasonable, we commit ourselves to further enjoying (enjoining) Us. Through this process, Us becomes a tangible, trustable authority in our lives. It lets us discover the feelingful wisdom of Us within and about us. To this end, the World Peace University Department of Integrated Ecology develops self-guiding nature-connecting training materials, workshops, internships and dialogues. They work because connecting with a wild rose offers twelve times more multi-sensory aliveness and integrity than does just seeing its photograph. They let Us itself validate and intensify our rewarding sensory connections with Us.

Established in 1985, the World Peace University, a non-governmental organization of the United Nations, educates for peace, social justice, food sufficiency and environmental and personal balance. To stop our vicious circles of conquest, the University inserts a peace component in all courses and disciplines. This differs from the tradition of offering learning for learning's sake without effectively addressing the known or possible adverse effects of what and how we learn. Uniquely, the University offers a unifying integrated ecology. It enables psychology and psychotherapy to heal the pain of our torn, sentient natural bonds to Us by sensibly re-connecting these bonds to their nurturing origins in Us. The program offers interpersonal activities in natural areas, activities based on modern knowledge, omissions and problems, not on those of 
other times, places and cultures. It seems insane that some authorities view the value of our nature-connecting methods and materials as suspect, however, R. D. Laing noted "Insanity is a perfectly rational adjustment to an insane world."

\section{The Process: Learning about Us from Us}

Integrated Ecology not only enjoins people with Us, it also helps us cope with internal and external forces that block enjoinment (enjoyment). It works in the natural areas of parks, backyards or back country. There, its activities reverse apathy, abandonment and disbelief by creating thoughtful, nature-sensitive moments. In these safe, non-languaged periods participants attune with and are nurtured by nature's non-verbal attractions and wisdom. Embraced by Us, our wanting, withdrawn natural senses awaken, play and intensify. Additional reinforcement activities empower our reasoning and language skills to articulate, strengthen and sustain these attractive sensations. Repressed inborn feelings of love, balance and understanding blossom into awareness. Natural self-respect, responsibility and sanity crystallize new personal integrities. The activities work best when done with a facilitator and shared with others since it is people's reasoning and approval that often allows us to learn, as well as un-learn, our habit of devaluing our natural senses.

\section{Some Activities and their Implications}

Our extreme indoor time and conditioning limits our thinking. It urges our 'three R's' senses - of sight, language and reason - to create stories that applaud our nature-closeted environment and creativity. We culture these three senses to dominate our perceptions and thereby reinforce our separation from Us. To offset their dominance, an integrated ecology activity connects us directly with Us by having participants limit their habitual dependency on language, sight and memory while in a natural area.

Upon conclusion of the activity, participants share what they sensed and felt. Their non-verbal, non-sighted, non-reasoning, non-judgmental experiences in the non-verbal natural world give other parts of Us the opportunity to come into awareness. Through this activity alone, within ten minutes, a group of participants usually validate that they experience over 35 different sensations and feelings such as: fun, warmth, direction, heartbeat, silence, trust, freedom, belonging, thankfulness, contentment, resonance, peace, forms, hunger, balance, color, timelessness, beauty, 
love, motion, purpose, direction, compassion, place, responsibility, nurturing, community, belonging to a greater whole and many more. Each of these senses is an aspect of Us in action. A compiled reaction is:

"Each sense felt good, each was an attraction to Us in the environment, my partner and myself. I was able to turn off my internal dialogue and sense that another world is here within and around me, one that teaches beyond what I can imagine or express. That world felt interesting, inviting and serene; I wanted to share it with my partner; I sensed an increasing responsibility, trust and oneness with myself, my partner and nature; I heard and felt more intensely."

Since Aristotle, our stories have taught us that we know and learn from five senses: touch, taste, smell, sight and sound. From my thirty years living in natural areas, my experiences with Us and the research of others, tell me we biologically inherit, and can know and learn from, not five, but over 53 distinct natural senses and feelings. But neither believe me nor documentation by physiologists, behaviorists and other investigators. For you, what we report is just more mediation (Cohen, 1993; Murchie, 1978; Pearce, 1980; Rivlin and Gravelle, 1984; RoveeCollier, 1992; Samples, 1976; Sheppard, 1984; Spelke 1992; WynneEdwards, 1991). I invite you to disregard us and simply trust your own unedited sensations in natural areas. Doesn't Us endow you to sense Hunger? Thirst? Compassion? Place? Nurturing? Color? Community? Space? Sex? Language? Gravity? Form? Motion? Including our "normal" five senses, this makes eighteen different senses. And if this observation interests you, it indicates that your sense of Reason is alive and challenged. There's a minimum of thirty-four more natural sense groups including: electromagnetism, direction, season, hormonal, distance, self, fatigue, trust, camouflaging, consciousness, music, esthetics, belonging to a larger whole. Each natural sense is an evolutionary memory, a distinct raw sensation, a feelingful natural attraction, a unique inherent way of knowing and registering relationships. Each is a singular expression of aliveness, being and surviving that pervades and connects nature within and without. These natural senses are of, by and from Us, not humanity alone. We inherit and share them with and through the global life community. Their attraction energies fuel the vital flow of Us through us.

Too often we teach our consciousness to mainly recognize labels and stories. We lose conscious contact with our natural sensitivities and 
feelings when we learn to label them adversely. However, no matter how we manipulate, label or redefine them, we feel natural senses. To remind readers of this, I italicize each sense. To gain conscious contact and enjoin with Us, we must learn to validate, strengthen and heed each natural sensation and feeling.

Sensory, non-languaged communication normally pervades interconnects and balances the global life community; even minerals display responsible attractions and sensitivities. For this reason it makes sense to spend connective time in natural areas rather than with sensory-limited nature videos, imageries and recordings. Validating and strengthening the many natural senses that a natural area awakens in us, connects us with the reality of Us. It offsets our limited indoor stories. It allows us to know Us as Us knows itself.

Sensing the Unity of Us

Each natural sense is a survival attraction that originates as Us branches and diversifies. For example, an organism living in the sea has little need for sensing the equivalent of thirst. But, if an organism evolves as a land animal, a natural sensory attraction similar to thirst simultaneously evolves in the genetic code to connect the organism and water. Without the essential (e-sense-ial) sense to know or remember that it needs water, the organism dies. We register this network of raw sensory attraction connections through our many anatomical, neurophysiological and perceptual attributes. Each natural sense signals some vital connection with Us. That signal, like Us, is always available in the "now," the present moment, never the imagined past or future.

Although we don't know how plants, animals or minerals register natural senses, we do know that we feel them. We assign different labels to our natural feelings. We call them: attractions, loves, sensations; affinities, spirits, resonance, invitations, callings, intuitions, god, communications, affections, blessings, bonds, higher power, natural wisdom, Us. But no matter what we call them, our natural senses and feelings are facts. Senses like thirst, place and nurturing and their good fulfillment feelings are as scientific, real, true and provable as are rocks, water, and pinching ourselves. We are normally born with our natural senses intact and healthy (Pierce, 1980); they constantly connect us to unconditional pleasure and fulfillment in Us. The fulfillment of natural senses in congress produces responsibly balanced good feelings. In contrast, single sense fulfillment alone, or general non-fulfillment, produces frustrated desires for responsible sensory satisfaction. 
Integrated Ecology recognizes that our natural senses and feelings are our multiple personality, our array of selves, the true nature of our "inner child." Each natural sense has value for each makes its special contribution to stability, survival and sanity. Since we didn't invent natural senses and we can't know them solely through language, each sense mystifies our closeted awareness. Each enriches our lives for as Albert Einstein said "The most beautiful thing we can experience is the mysterious. It is the source of all true art and science." and "The foundation for inner security is... to free ourselves from this prison by widening our circle of compassion to embrace all living creatures and the whole of nature and its beauty."

Although researchers continuously validate our natural multi-sensory nature, its full significance remains unrecognized because our culture's indoor story encourages us to conquer, not validate, Us. However, our demeaned natural senses are the vital but missing facts in a responsible story about Us, about how and when to best act where. They are present in every infant, but we neither respect, exercise or support them sufficiently. As Carl Jung noted, "Our feelings are not only reasonable, they are as discriminating, logical and consistent as abstract thinking."

The senses of reason, language and consciousness are approximately $12 \%$ of our inherent means to know and relate to Us. Too often we train these senses and their stories to dominate, rather than nurture, the 49 other natural sense groups that make up the remainder of our mind. Too often society pays us well to do this, even when we recognize that the stories misguide us. Cigarette advertising or stressful self expectations serve as examples.

\section{Self Regulation}

One integrated ecology activity has participants drink water from raindrops, snow or a spring. Observation and discussion lead them to see that, as it does in all organisms, water from the environment flows into us, through us and out of us. But during this process, neither an excess nor shortage of water enters or leaves us. We neither explode, bloat nor dehydrate. What vital regulator(s) attracts, guides and balances water through us? Each of us is familiar with it but it's often suppressed from sight and mind. It surprises most of us to discover that the water attractor and regulator we know best is thirst, a natural sense, one of the many sensible expressions of Us. Like every other natural sense, and like a control valve, by activating or deactivating thirst regulates. For example, 
thirst not only motivates us to drink the Planet's water, but quenched thirst feelings innately know and tell us when to stop drinking. Each natural sense remembers and is part of nature's eons of life experience. When we feel natural sensations, we sense the global life community, including the mineral kingdom, nurturing and balancing its flow in and through us. That flow is an emotion called survival. When the flow through us stops, we die and begin to flow into other lives. In congress, natural senses further govern the flow by modifying each other. For example, our thirst is affected by heat, (temperature), salt content (chemical), fatigue, and sight, sound, taste or even thought (language, reason, consciousness) of water. Our congress of natural senses welcomes every diverse contribution to making sense. In concert, the 53 natural senses form a trustable consensus, a common sense and consent that supports life's and our life's survival. When in congress, every different sense offers knowledge that sensibly informs and stabilizes Us within and about us. Language and reason make their contribution too. For example, label a glass of pure water "sewage" and only illiterate, blind or stupid people will comfortably drink it, for reason dictates that it's unreasonable to do so.

\section{Substantiation}

Integrated Ecology substantiates the wisdom of Us by validating that Us produces no garbage. This is no accident. Rather, it's because Us only grows from attractions between things. Everything natural is attractive including each of us. Nothing is rejected, unwanted, negative, unattractive or unnecessary, so in nature there's no such thing as garbage, pollution or waste. That's unconditional love in action. Ecology shows us that when we make a value judgment about Us and remove what appears to be a detrimental part of Us - for example, a predator - the total community, in time, deteriorates rather than improves. Again, this insinuates that everything is attractive, wanted and needed. It explains why fully sensing Us in us catalyzes self-respect and self-esteem. To this end, an activity asks a participant why they like a flower that attracted them. "I like the flower because its sensitive, it's beautiful and it gives of itself to many different lives" says Paul. I reply: "Since you know that you and the flower are Us, now say those words about yourself and see how it feels." Paul responds, "I like myself because I'm sensitive, I'm beautiful and I give of myself to many different lives. Hey, that feels great - strange, yet true too. That flower spoke to me!" The activity awakened Paul's natural senses including: color, belonging, nurturing, 
place, language, reason, community, esthetics consciousness, compassion, power, ethics, appreciation and trust. The natural world abounds with support statements. Each of our other ninety-six nature connecting activities similarly let contact with Us catalyze self-esteem.

\section{Nature Negatives}

We disconnect from Us because our external and internalized authorities prejudicially signal there is harm in nature. In one activity, participants go to a natural area and seek the fears and discomforts found there such as thorns, rough surfaces, mosquitoes, cold water, harsh weather, heights, dangers, and strangers. Later they identify the discomforts they sense from people they know, discomforts such as anger and punishment, or being controlled, rejected, ignored assaulted or exploited. Integrated Ecology suggests that since Us only consists of natural attractions, Us can't be negative (Cohen, 1993). When we sense discomfort of any kind, the natural world is actually supporting us. For example, because Us treasures our life, the discomfort of thirst is actually Us trying to keep us alive by signaling us to connect to water. Discomfort always signals that some natural marriage is out of balance, some natural sense senses its excessive separation from Us. Each discomfort always says: "For survival, seek, enjoin and follow the natural attractions that now call you. Gain their fulfillment, attain the stability of Us again." Participants discover that the natural world doesn't irritate us, our unfulfilled natural senses do. This discovery helps participants remove defects and shortcomings wrongly assigned to nature including their inner nature, the little child within them. Participants re-examine the nature negatives they sense in the activity and their lives. They learn to perceive them as attractive callings. Consider two examples: "The discomforts from cold, wet weather signaled me to satisfy my attractions to a warmer, drier place. I feel good knowing that I can enjoyably relate by heeding warning signals from Us and by seeking comfort elsewhere in Us." "My fears and mistrusts of people tell me to risk seeking and enjoying Us within them, others and the environment rather than focus on the discomforts they present."

Our nature negatives often symptomize that our true inner nature remembers its estrangement from Us. When Us in us senses its abandonment, we interpret nature as negative rather than as a provider of supportive directional signals and peaceful survival. To reverse this situation participants further engage in nature-connecting attractions. In time, they substitute newly revived natural attraction joys for their 
abandonment fears, which then wane. Participants learn to recognize that their discomfort from loneliness is really an attraction for responsible sensory relationships. Depression is a calling for more intense, safe sensory satisfaction. Anger is a strong attraction to being nurtured, not abandoned, by a stabile life support community. We dislike people we sense to be sensorially injured for their lack of sensitivity prevents us from fulfilling our attractions to Us in them and vice-versa. We try to avoid them because we sense that their insensitivities are dangers and abandonment-hooking risks. Engaging in mutually shared nature-connecting activities with them and others enables Us to build greater sensitivity, sensory satisfaction, and responsible interpersonal relationships, even with negative people.

Normally, many senses come into play and support us when we sense discomfort. For example, fulfillment from our senses of community, place, compassion, nurturing, space, consciousness, reason, mobility, belonging to a greater whole, self, esthetics and many others ordinarily offset any one passion or discomfort from becoming destructively runaway. But when the intersensory self-regulation process ceases because other supportive senses have been hurt into inertness, normal balanced fulfillment is absent. We become "disturbed," "insensitive," or "mentally or emotionally imbalanced." Excessiveness fills the void. We sense an even greater need and dependence on our comforts, artifacts and destructive outlets. For example, we overeat because we seek excessive fulfillment from two senses (taste and hunger) to pacify the unfulfilled cravings of other disconnected senses. Greed and violence flourish because when we are unbalanced we want, and when we want there is never enough. You show me apathetic, violent or greedy people and I'll show you people with injured natural senses. Repeatedly reconnecting them to Us rejuvenates these senses and the good feelings they bring.

\section{Dealing with Abandonment}

One activity asks participants in a natural area to inhale and recognize that as they breathe the atmosphere for their survival, Us breathes them to help sustain all of life. This relationship is healthy co-dependency at its finest. As participants exhale, I tell them to disconnect from Us by holding their breath. Their inner nature responds to this disconnection/abandonment with suffocation feelings. These feelings at first call, then demand that participants begin breathing again, no matter their age, sex or occupations; race, religion or nationality. The 
feelings express that Us unconditionally loves the participant's life. The facilitator or guidebook says: "My instructions, my language and reasoning, not Us, directed you into not breathing. Choosing to comply with my requirements disconnected you from Us. You had and always have the choice to either heed or disregard me. As long as you continue to choose disconnection, you experience natural discomforts that tell you to follow your natural attractions." Realizing this, participants choose to re-connect through their natural respiratory (re-spiriting) sense. They breathe again and they sense Us in them respond with good feelings. They feel inspired (spirit in) so they don't expire (spirit gone). Together we and Us conspire (breathe spirit together) to create good feelings, and to peacefully promote life by educating and re-programming the disconnectors in our mentality and community. I show participants that the ancient word for air is psyche which also means spirit. I remind them that only our natural connections with Us, not with air-conditioners, humidifiers and deodorants, create and sustain comfortable respiratory feelings as well as fresh air for us and Us.

When our excessive indoor ways disconnect one or more of our natural senses from Us, they interrupt our us-Us sensory attraction connections and we feel pain. That's when and why children cry. Our sentient inner nature registers being abandoned, assaulted and engineered. It dispels these hurts by hiding them subconsciously. To our cost, our participation in responsible relationships collapses whenever an expectation or rejection hooks these subconscious hurts. Fear and apathy arise and further disable us. Although over forty per cent of the public seeks some sort of counseling to help them deal with these nature-estrangement phenomena, most counseling takes place entirely indoors. In this way it sustains, rather than reduces, isolation from Us.

As long as we let our cultural story and our internalizations of it separate us from Us rather than enjoin us with Us, the vicious circles of our lives continue. Nature-connecting activities interrupt this destructive process. They insist that our reason and language senses learn to seek, validate, resonate with, trust and strengthen our fifty-one other natural senses. Then connecting with Us becomes possible anywhere, anytime. This allows Us in us to feel content to remain in us rather than leave our being and enjoin with Us in the environment. We often call the leaving process "death," "cancer" "self-destructive" or "stress related" It's actually our inner nature attempting to escape hurtful cultural blockades, to more fully embrace the fullness of Us. 
When we seek the unadulterated perfection of Us in a natural area, it often mirrors our internal natural sensory disconnections. Not accidently, specific natural attractions appear attractive in a natural area at any given moment depending upon our conscious or unconscious moods, needs or problems. For example: While sensing a natural area, the grandeur of soft, peaceful, billowing cloud formations attract Bill. However, following an argument with his wife, he finds that the clouds now appear ominous and, in addition, the discomforts of a thistle's spines attract him. Alarmed by his discovery that he's that he's attracted to pain, Bill learns a new story, one saying "Follow other natural attractions of Us." Soon, good feelings from new attractions gently guide him and his wife to the fullness of the cloud's, thistle's and his own natural integrity. He again senses Us, the adaptability and enduring attractions that he, the clouds, thistle and his wife hold in common. By this process, incorporating contact with Us makes our felt negatives into positives and possibilities.

\section{Origins and Solutions}

Anthropologists suggest that, culturally and biologically, humanity evolved in the warm, relative stability of Earth's womblike tropical areas. There, in "Eden," we successfully taught ourselves to suckle from Us by culturally intensifying, heeding and revering nature's ever-changing callings. Through this process most indigenous cultures survived harmoniously, even when climatic conditions changed due to glaciation, or when they migrated into temperate areas. However, western civilization took a different path. Through reasoning and language stories we designed sense-fulfilling warmth, shelter and food growing techniques. We technologically built artificial simulations of the tropics, our agricultural, indoor world. We learned to applaud stories that said "Conquer Us" - short-sighted, sterile tales that produced tropic-like stability (Sheppard, 1984). Today, when we think that our nature-estranged stories, not Us, sustain our survival, our thinking continues to pave paradise, produce garbage, and initiate wars within and about us.

Integrated Ecology enables the counseling process to make a desperately needed contribution to environmental awareness and responsibility. Counseling with nature unbonds us from destructive artifacts and re-bonds us to natural areas. It gives these areas added value as places to find Us. Too often our indoor limits teach us to only trust environmentally limited ideas. For example, when we learn to mostly know a 
natural area as economically valuable raw materials or square feet of real estate, we tend to sense it as an expendable, exploitable, economic object, a commodity or resource to develop or improve. This differs from sensing the same natural area as Us, a personal fulfillment, a friend, a profound wisdom, a community, a home of all species and unconditional love, our other body, a teacher, a planetary mother, a biological necessity for one's ethical, physical and emotional well being, spirit in action, a celebration of four billion years of relating, unedited higher power, ever-changing perfection or a sacred place. The values we assign to natural areas produce vastly different long term effects on them. Tangible sensory contact with, and support from Us within and without lends credence to protecting Us's manifestation in the natural world.

To believe that we can find lasting peace and sanity while continuously injured by our estrangement from Us defines madness. Through sensory nature connecting seminars, workshops, courses and home study training programs, the Department of Integrated Ecology enables the perfection of Us itself to help reflect and correct our estrangement and its discontents. The process encourages our reasoning and language senses to seek and validate attractive connections with Us. We discover responsible stories and sensations that move us. We begin to walk our talk, to live in our ideals and the peace of Us.

\section{References}

Cohen, M. J. (1974). Our classroom Is wild America. Freeport, ME: Cobblesmith.

Cohen, M. J. (1988). How nature works. Walpole, NH: Stillpoint.

Cohen, M. J. (1990). The World Peace University field guide to connecting with nature: Creating moments that let earth teach. Eugene, OR: World Peace University.

Cohen, M. J. (1993). Well mind, well earth: 97 environmentally sensitive activities for stress management, spirit and self esteem. Roche Harbor, WA: World Peace University Press.

Murchie, G. (1978). Seven mysteries of life. Boston: Houghton Mifflin.

Pearce, J. (1980). Magical child. New York: Bantam.

Rivlin R., \& Gravelle, K. (1984). Deciphering the senses. New York: Simon \& Shuster.

Rovee-Collier C. (1992). Infant memory shows the power of place. Developmental Psychology (March). Quoted in Science News, 141, (16), p. 244.

Samples, B. (1976). The metaphoric mind. Reading, MA: Addison-Wesley. Sheppard, P. (1984). Nature and madness. San Francisco: Sierra Publications. 
Spelke, E. (1992). Infants signal the birth of knowledge. Psychological Review (October) as quoted in Science News, 142 November 14, 1992, p. 325. Wynne-Edwards. (1991). Ecology denies darwinism. The Ecologist, MayJune, England.

Michael J. Cohen, Ed.D. founded and coordinates Project NatureConnect, a continuing education workshop and home study program of the World Peace University where he chairs the Department of Integrated Ecology on San Juan Island, Washington. For thirty-three years he has established and directed degree granting environmental outdoor education programs for the Trailside Country School, Lesley College, and the National Audubon Society. His books and articles include the award winning Connecting With Nature which is included in his 1993 self-guiding training manual Well Mind, Well Earth: 97 Environmentally Sensitive Activities for Stress Management, Spirit and Self-esteem. Address correspondence to: Michael Cohen, P.O. Box 4112, Roche Harbor, WA 98250. 